\title{
Patient's Knowledge Assessment on Diabetes and Self- Care Practices Among Older Adolescents with Type 1 Diabetes Mellitus in Malawi
}

\author{
Etta Chimbe Phiri, (MSc Child Health Nursing) \\ Mzuzu University, Malawi \\ Gladys Msiska, (PhD) \\ Kamuzu College of Nursing, Malawi \\ Lucy Ida Kululanga, (PhD) \\ Kamuzu College of Nursing, Malawi \\ Balwani Chingatichifwe Mbakaya, (MPH)
}

St John's College of Nursing, Malawi

Doi: 10.19044/esj.2017.v13n33p429 URL:http://dx.doi.org/10.19044/esj.2017.v13n33p429

\begin{abstract}
Adolescents with Type 1 Diabetes Mellitus (T1DM) face risks of long-term health complications due to difficulties in achieving and maintaining target glycemic control. The study aimed at assessing knowledge on diabetes and self-care practices among older adolescents with type 1 diabetes to identify significant knowledge gaps. Gathering information from adolescents on how much they know about the condition and their self-care practices would help identify significant knowledge and self-care gaps. A quantitative descriptive cross-sectional study design was used. Convenience sampling was employed to recruit 46 adolescents with TIDM from two tertiary hospitals in Malawi. Data were collected using interviewer administered questionnaire from January to March, 2014, and analyzed using SPSS version 20 . The study results revealed inadequate knowledge amongst the adolescents on issues pertinent to self-cares. 58\% (42/72) had inadequate knowledge on managing hyperglycemia, 61\% (28/46) were inappropriately doing the self-monitoring of blood glucose resulting in high admission rate with $44 \%$ being admitted 3-4 times and $11 \%$ more than 7 times in a year. Linear regression showed a significant association between age and number of admissions $(P=0.022)$ hence as age increases, so does the number of admissions. $78 \%$ (36/46) were not adequately counseled on diet plan. Excessive thirst and frequent urination were the most mentioned signs of Type 1 Diabetes Mellitus 24\% (45/191). Ulcers on the feet were the most mentioned complication 33\% (42/127.
\end{abstract}


Majority of the adolescents $(70 \%, 32 / 46)$ knew why changing insulin injection site is important. The study identified a significant need to develop relevant health education materials on diabetes and self-care practices for adolescents within Malawi to help them manage the condition hence averting long term complications.

Keywords: Older adolescent, Type 1 Diabetes Mellitus, Self-care practices, Glucose monitoring

\section{Introduction}

In 2011, there were 366 million people worldwide with diabetes, 183 million $(50 \%)$ with diabetes undiagnosed and 4.6 million deaths with more than $80 \%$ of these deaths occurring in low and middle-income countries (WHO, 2013). It was estimated in 2010 that 37,500 children under 14 years of age in Africa had type 1 diabetes and 6,100 new cases will be diagnosed (Motala and Ramayira, 2010)

Comprehensive data on the magnitude of Type 1 diabetes mellitus among adolescents in Malawi is missing, though a good number of adolescents who form $24 \%$ of the population are being diagnosed with diabetes. It is difficult to estimate the prevalence and incidence of diabetes among children and adolescents in Malawi due to lack of data in many health facilities though it is put at around $15 \%$ of the adult population (Mtambalika, 2012).

The goals for the management of TIDM in adolescents are to prevent Diabetes Ketoacidosis (DKA), prevent severe hyperglycemia and hypoglycemia, maintain normal growth and development and prevent longterm diabetic complications (Hoffman, 2004). This is done by following selfcare practices which include regular exercise, taking recommended diet, proper intake of prescribed medications and blood glucose monitoring (Sigurdardottor, 2005).

While the care regimen is complex, patients with good diabetes selfcare knowledge and behaviors can attain excellent glycemic control (Delamater, 2006). For this to be done, patients need to have adequate knowledge on self-care practices despite the fact that literature concludes limited knowledge about diabetes among patients (Kiawi, et al., 2006). Mufunda, Wikby, Björn, and Hjelm (2012) state that with the everdecreasing health care resources especially in developing countries including Malawi, the need for self-care management becomes paramount. Gulabani, John and Isaac (2008) indicated that increasing patient knowledge regarding disease and its complications has significant benefits with regard to patient compliance to treatment and to decreasing complications associated with the disease. Adolescents with diabetes have been overlooked despite the unique 
challenges their care presents (Halvorson, Yasuda, Carpenter, and Kaiserman, 2005). The complex regimen like monitoring of blood glucose, insulin injections and dietary restraint becomes overwhelming and timeconsuming for them (Wysocki, Lochrie, Antal, and Buckloth, 2011). This is so, as during this stage, physical, mental and emotional developments coincide with their battle against a chronic disease (Adeyemi, Rascati, Lawson, and Strassels, 2012). They prefer to live a normal life like their friends affecting their compliance. In addition, incomplete knowledge and understanding of treatment regimens and premature shift in responsibility for management from parents to adolescents all affects practices in diabetes management (Borus and Laffel, 2010). This put them at a high risk of developing complications which include disorders like coronary artery disease, cerebrovascular and peripheral vascular disease, nephropathy, lower-extremity amputations, infection and ketoacidosis (Allen, et al., 2010). This study therefore, aimed at assessing knowledge on diabetes and self-care practices among older adolescents with type 1 diabetes in Malawi in order to identify significant knowledge gaps and plan make appropriate recommendations.

\section{Methods}

The study employed a quantitative approach using descriptive crosssectional design and was conducted at two referral hospitals, Kamuzu Central Hospital in Lilongwe and Queen Elizabeth Central Hospital in Blantyre. The study population was drawn from adolescents with type 1 diabetes aged 15-19 years who came for follow up at the diabetic clinics. Convenient sampling was used to recruit 46 adolescents after the approval by College of Medicine Research and Ethics Committee (COMREC). For those 15-17 years, an assent form was filled by the participants and consent sort from the guardian or clinic clinician. Those 18-19 years, consent was given by the participants. The inclusion criteria were as follows; adolescents 15-19 years; with type 1 diabetes mellitus; diagnosed 6 months and above.

Data were collected using a questionnaire developed by the researcher based on the literature from the peer reviewed articles, adaptation of some questions from Michigan Diabetes Knowledge Test (MDKT), which is a validated tool from the Michigan Diabetes Research and Training Centre (Fitzgerald, Funnell, Anderson, Nwankwo, Stansfield, \& Piatt, 2016) and practical issues identified at Queen Elizabeth Central Hospital (QECH) pediatric diabetes clinic. The questionnaire looked at general knowledge on diabetes, complications and self-care practices. Data were processed using SPSS version 20 with subsequent descriptive analysis. Where variables were suspected to relate, cross-tabulations were done and tests for significance of 
the relationship were applied. Statistical analysis was performed at $5 \%$ significant level.

\section{Results}

\section{Demographic characteristics of participants}

Forty-six (46) adolescents participated in the study, 20 from Kamuzu Central Hospital $(\mathrm{KCH})$ and 26 from QECH. Sixty-three percent (29/46) were males and $37 \%(17 / 46)$ were females and mean age of the participants in years was $17(\mathrm{SD}=1.365)$. In terms of education, 46\% (21/46) of the participants were in secondary school, 35\% (16/46) in primary school and only $20 \%$ (9/46) in college. The results showed a statistically significant difference $(p<0.05)$ in the sex of the participants, which might indicate that more males are affected with diabetes than females. The period of having the diabetes ranged from 6 months to 1year $(15 \%, 7 / 46), 2$ to 5 years $(22 \%$, $10 / 46), 6$ to 10 years $(22 \%, 10 / 46)$ and more than 10 years $(9 \%, 4 / 46)$.

\section{Number of admissions and reasons for admission}

All participants $(58 \%, 46 / 79)$ had previously been admitted due to hyperglycemia, $10 \%$ (8/79) due to hypoglycemia, 9\% (7/79) due to abdominal pain and only $23 \%$ (18/79) were admitted due to other complications. Comparing the facilities, $\mathrm{KCH}$ had a few participants, $13 \%$ (6/46) being due to other complications than QECH who had double $26 \%$ (12/46). Twenty eight percent (13/46) of the participants had been admitted 1-2 times, 44\% (20/46) 3-4 times, 17\% (8/46) 5-6 times and 11\% (5/46) 7 times and more. See figure 1 below. Linear regression was performed to model the effect of age on the number of admissions which yielded a significant effect $(P=0.022)$. This means that as age increases, so does the number of admissions. Further results showed no significant difference in the mean number of admissions between male and female participants ( $\mathrm{df}=$ $38.105, p=0.2983)$.

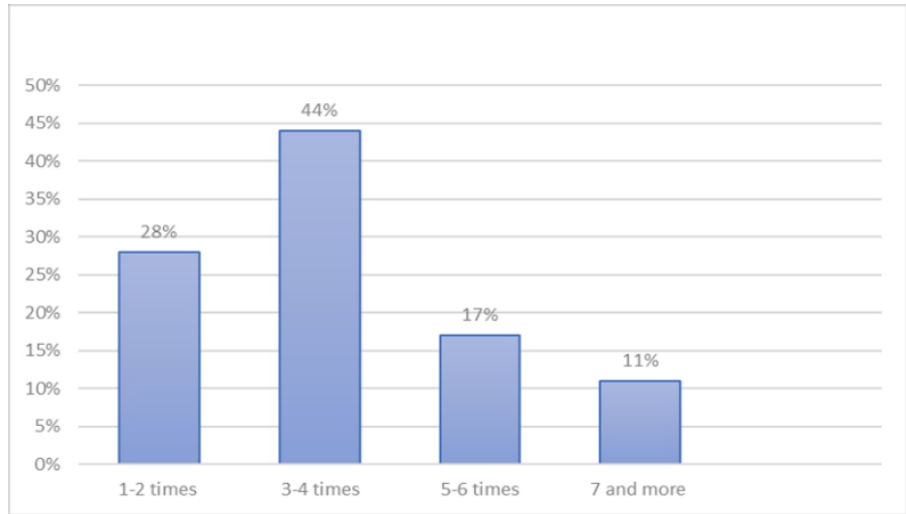

Figure 1: Bar graph indicating number of admissions 


\section{Knowledge on diabetes mellitus: Causes, signs and complications of diabetes}

Sixty-three percent (29/46) knew the cause of diabetes whilst $37 \%$ (17/46) associated type 1 diabetes with eating a lot of sugar foods. On signs and symptoms excessive thirst and frequent urination were the commonest signs mentioned (45/191) and on complications, ulcers on the feet was the commonest complication mentioned by $33 \%$ (42/127), eye damage $30 \%$ (38/127), neuropathy 14\% (18/127) and least was abdominal pain (9\%, 12/127). This showed participants had good knowledge on the complications of diabetes. Only 22\% (10/46) participants at QECH reported being assessed for diabetes complications during clinic follow up visits and none at $\mathrm{KCH}$. There was a significant relationship on education and knowledge on diabetes $(p=0.02)$, those doing tertiary education had better knowledge than those in primary school. See table 1 below.

Table 1: Signs and complications of type 1 diabetes mellitus

\begin{tabular}{cccc}
\hline & \multicolumn{2}{c}{ Description } & Responses \\
\cline { 3 - 4 } & & $N$ & Percent \\
\hline Signs of type 1 & & 45 & 24 \\
diabetes & Excessive thirst & 34 & 18 \\
& Feeling tired/weak & 45 & 24 \\
& Frequent urination & 32 & 17 \\
Loss of weight & 35 & 18 \\
& Excessive hunger & 191 & 100 \\
\hline Complications of & Total & 12 & 9 \\
diabetes & Abdominal pain & 38 & 30 \\
& Eye damage & 42 & 33 \\
& Ulcers on the feet & 17 & 13 \\
& Kidney damage & 18 & 14 \\
& Nerve damage & 127 & 100 \\
\hline
\end{tabular}

Causes, signs, symptoms and management of hyperglycaemia and hypoglycaemia

On causes of hyperglycemia, most participants 29\% (34/119) mentioned injecting too little insulin as the cause, forgetting to inject insulin was mentioned by $20 \%$ (24/119), not following diet plan by $21 \%(25 / 119)$, little physical exercise by $19 \%$ (23/119) and being ill by $11 \%$ (13/119). On hypoglycemia, 23\% (25/111) named too much physical activity as the cause, injecting too much insulin by $20 \%$ (22/111) and skipping meals by $16 \%$ $(18 / 111)$

Frequent urination was the commonest sign of hyperglycemia mentioned $25 \%(33 / 133)$ and feeling hungry was the commonest sign mentioned for hypoglycemia by $28 \%$ (28/101). Forty-eight percent (48\%, 
22/46) of the adolescents indicated difficulties in differentiating the signs and symptoms of hyperglycemia from hypoglycemia. Pearson chi-square test showed a significant relationship on effect of education on isolating signs and symptoms of hyperglycemia and hypoglycemia $(p=0.03)$. There was no significant relationship between the type of facility and knowledge on identifying the signs and symptoms of hyperglycemia and hypoglycemia $(p=0.80)$.

Despite the participants being familiar with the signs and symptoms of hyperglycemia, the results show that they were not conversant with the management. On managing hypoglycemia, eating sweets was mentioned by $61 \%$ (46/75), 17\% (13/75) mentioned drinking a half cup of squash or sugar solution. On hyperglycemia management, only 6\% (4/72) injected another dose of insulin and 58\% (42/72) went to hospital without doing anything at home.

Figure 2: Signs of hyperglycemia and hypoglycemia

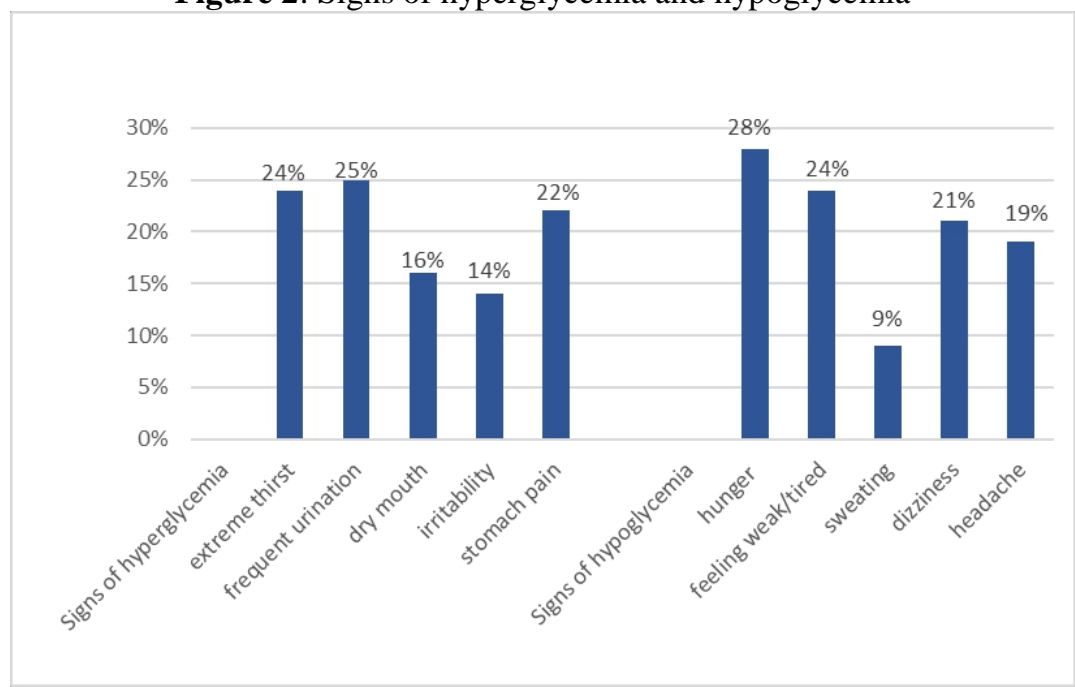

\section{Insulin administration and storage}

Majority $64 \%(39 / 61)$ of the participants were injecting themselves the inulin. The thigh was the commonest injection site $(32 \%, 46 / 143)$, abdomen 29\% (42/143) and least was the buttock 13\% (18/143). Seventy percent (32/46) knew the importance of changing insulin injection site but only a few $(26 \%, 12 / 46)$ were actually rotating the injection site with $22 \%$ (10/46) using mostly two sites for fear of pain. There was a significant statistical relationship between insulin administration and type of facility $(p=0.02)$ and age $(p=0.01)$. Those at $\mathrm{QECH}$ were more knowledgeable on insulin administration than those at $\mathrm{KCH}$. 
Table 2: Knowledge on insulin injection

\begin{tabular}{cccc}
\hline \multirow{2}{*}{$\begin{array}{c}\text { Description } \\
\text { Who injects the insulin } \\
\text { at home }\end{array}$} & Myself & $N$ & Responses \\
\cline { 3 - 4 } & Parents & 39 & 64 \\
& Brother/Sister & 11 & 18 \\
& Total & 11 & 18 \\
& & 61 & 100 \\
\hline Areas of injecting & & 13 \\
insulin & Buttock & 18 & 32 \\
& Thigh & 46 & 29 \\
& Abdomen & 42 & 26 \\
& Arm & 37 & 100 \\
\hline
\end{tabular}

Clay pot was the commonest storage site for insulin by $52 \%(24 / 46)$, $41 \%(19 / 46)$ used refrigerators and 7\% (3/46) stored their insulin in a cupboard. For those who used the clay pot, 58\% (14/24) reported not being sure if they were doing it right and those who used refrigerators, major challenge was the frequent interrupted power. All participants recognized the importance of putting on shoes at all times and 57\% (26/46) for checking the feet daily for cuts and sores though none did the daily check.

\section{Monitoring blood glucose}

Eighty-seven participants (40/46) recognized the need for monitoring blood glucose at home. Sixty-one (28/46) monitored blood glucose using symptoms of high and low blood sugar levels, $15 \%$ (7/46) were not doing any monitoring and 20\% (9/46) used blood glucose machine (glucometer). See figure 3 below.

Figure 3: Methods of monitoring blood glucose levels at home

\section{Blood glucose monitoring}

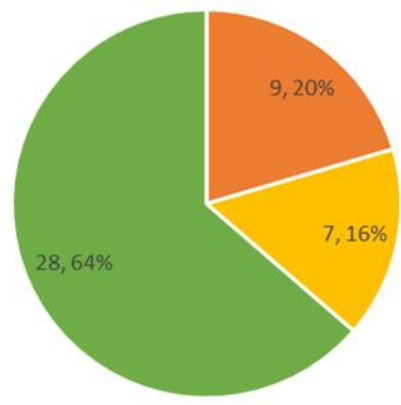

- Blood glucose machine $\quad$ = No monitoring $\quad$ - Signs and symptoms 


\section{Diet}

$52 \%(24 / 46)$ did not recognize the need for diet in glycemic control to manage the diabetes. Seventy eight percent (36/46) were not adequately counseled on diet plan resulting in 65\% (30/46) mentioning failure to manage the diet as a challenge. It was difficult for them to prepare balanced diet considering the amount, frequency and type of food they are allowed to eat to control the blood glucose levels.

\section{Support}

On support, psychological support was least provided by family members $(11 \%, 13 / 121)$ and health care providers $9 \%(11 / 119) .52 \%(11 / 21)$ also got psychological support from friends. See table 3.

Table 3: Support for managing diabetes

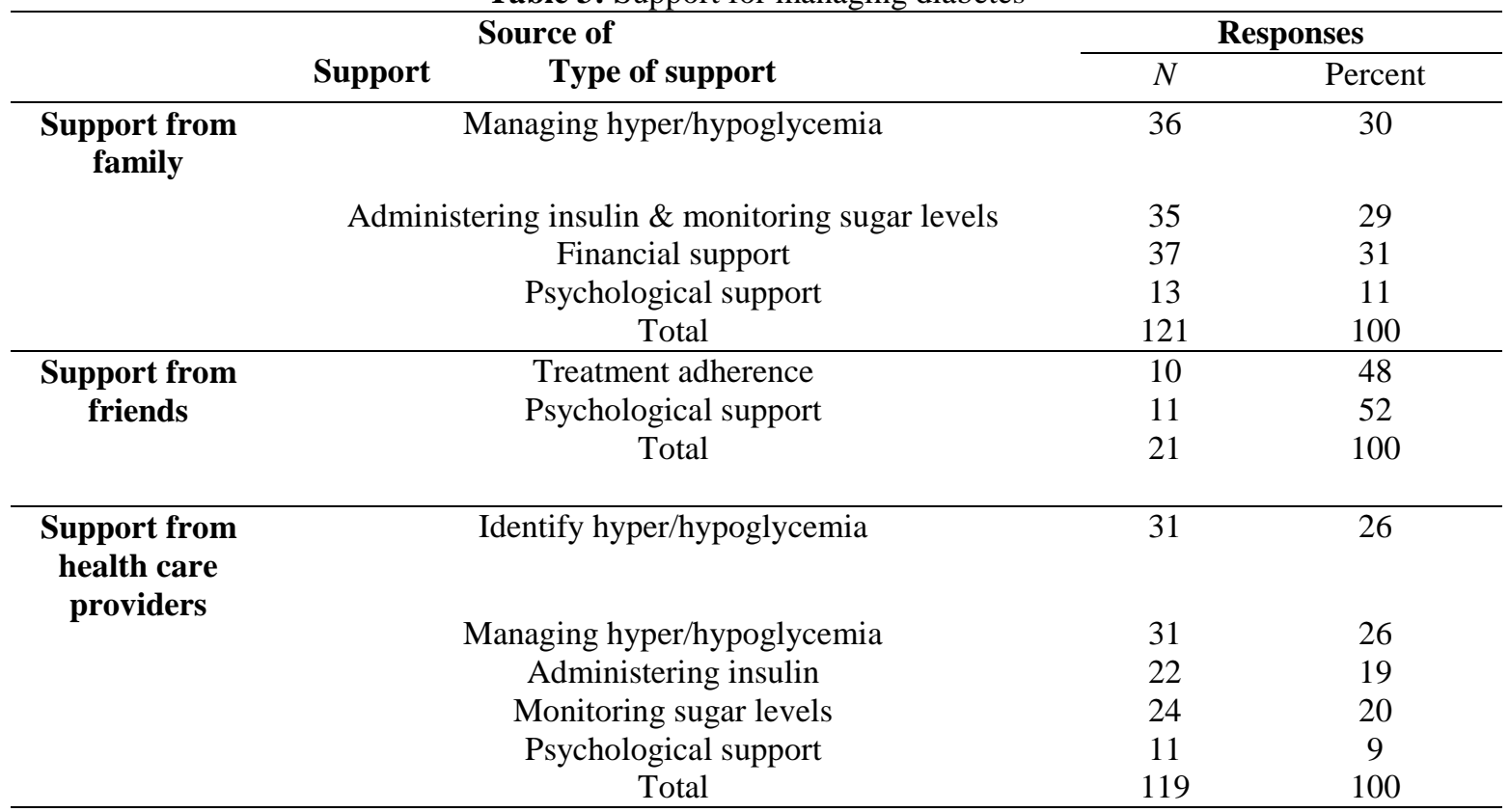

\section{Discussion}

The study findings show that all participants knew the management of hypoglycemia at home and eating sweets was commonly mentioned. The good knowledge on management and easy availability and affordability of sweets could have influenced the participants' fewer admissions due to hypoglycemia $10 \%(8 / 79)$. About 58\% (42/72) of the participants reported going to hospital when they felt their blood glucose level was high indicating the lack of knowledge in managing hyperglycemia at home. The adolescent patients need adequate information to manage their diabetes at home. In addition, the results showed that about $48 \%$ (22/46) of the participants had problems in clearly differentiating if what they were feeling were the signs of 
hyperglycemia or hypoglycemia. These findings agree with those in a study done by Chingatichifwe, Dodge, Chideme-Munodawafa, Mwale, \& Bvumbwe (2014), in which it was found that clients suffering from diabetes at Mzuzu Central Hospital in Malawi, displayed less knowledge regarding the definition, healthy lifestyle and complications of diabetes. Although identifying a symptom for hyperglycemia or hypoglycemia can be deemed easy owing to the fact that they feel them whenever fluctuation of their blood glucose level occurs, it might be difficult and they need to develop the skill to achieve this. Hence, the integrated support is then needed. Focus group discussions, visit to schools and multidisciplinary management at health facility level may help the adolescent patients to achieve the required skills to identify and manage hyperglycemia. In addition, the results showed a significant relationship between age and number of admissions $P=0.022$. Peer pressure, gaining independence mostly associated with adolescent period can be a result of the high number of admissions with age. A qualitative study by Carroll, Downs and Marrero (2007) revealed that selfglucose monitoring was viewed by many of the teens as the most inconvenient, disruptive, and least favorite aspect of having diabetes. Some stated social discomfort in testing in front of friends. Parents in all groups noted that as their children hit adolescence, it became more difficult to control their children's blood glucose monitoring. Their study aimed at learning from adolescents with diabetes and their parents whether mobile monitoring technology could help to reduce hassles associated with testing, improve compliance, and ease adolescent-parent conflict about testing behavior. This clearly shows how difficult it is to manage a chronic illness amongst adolescents hence requiring more support.

The failure to recognize the need of diet in controlling and maintaining blood glucose by $52 \%$ (24/46) of the participants could have contributed to consumption of non-recommended meals. 65\% (30/46) of the participants mentioned failure to manage the diet plan as a challenge they face in managing the diabetes. This together with the insufficient diet counseling could have resulted in diet incompliance contributing to the high number of admissions due to hyperglycemia, 58\% (46/79). In addition, the high number of admissions with 44\% (20/46) being admitted 3-4 times in a year. Dietary recommendations for type 1 diabetes advocate consumption of a healthy diet and maintenance of a balance between carbohydrate intake and insulin levels to achieve near-normal blood glucose levels (Bantle, et al., 2008). Abioye-Kuteyi, Ojofeitimi, Ijadumola and Fasanu (2005) in their study concluded that in settings where dieticians are scarce, physicians managing diabetic patients must be skilled in the dietary management of the condition and show commitment to it. Since in Malawi physicians only make up a smaller percentage of health care providers, an average of one physician 
for every 50,000 persons, most health education services being provided by nurses which have a nurse-patient ratio of 36.8 nurses per 100,000 populations (WHO, 2011; Hoffman, et al., 2012). This means nurses need to have necessary skills in counselling patients with diabetes.

The insufficient knowledge on diet plan amongst the participants could also affect adherence with diet recommendations. Literature has shown that despite the availability of effective therapies, adolescents with type 1 diabetes demonstrate poorer adherence to treatment regimens compared with other pediatric age groups (Borus and Laffel, 2012). This was also found in a cross-sectional study by Nansel, et al. (2012) where participants aged 8 to18 years demonstrated low adherence to dietary guidelines. All this shows how difficult it is for the adolescents to follow the diet plan and with no adequate information on meal planning it can only make the situation worse. Therefore, development of teaching aids to act as reference material when managing the condition at home is needed.

Findings indicated that $61 \%(28 / 46)$ of the adolescents relied on signs and symptoms of hyperglycemia and hypoglycemia to monitor blood glucose levels creating room for error. Clarke and Foster (2012) showed that for accurate results, electrochemical glucose meter systems (glucometers) are recommended for monitoring blood glucose and was only used by $20 \%$ (9/46) of the participants. Poverty could be one factor causing this challenge as most families could not afford them. The study results are similar to the study done in Urmia, Iran where they found that only two percent of the participants had weekly self-monitoring and financial barrier played an important role (Yekta, 2011). Self-monitoring of blood glucose is a cornerstone of diabetes care that can ensure patient participation in achieving and maintaining specific glycemic targets (Shrivastava, Shrivastava and Ramasamy, 2008). Ahola (2012) add that it provides information about current glycemic status, allowing for assessment of therapy response and guiding adjustments in diet, exercise and medication in order to achieve optimal glycemic control.

Sixty-four percent (39/61) of the participants were injecting themselves the insulin the thigh being the commonest site by $32 \%(46 / 143)$. Only 22\% (10/46) reported using only two sites for insulin injection for fear of pain. These findings are in agreement to the study by Patton, Eder, Schwab and Sisson (2010), where fear of pain was the reason mentioned for using one injection site by $22 \%$ (10/46) of the participants. Rotating injection site is necessary to prevent skin damage that can affect absorption. Alemzadeh, Loppnow, Parton and Kirby (2003) agrees that lipohypertrophy caused by injecting insulin on the same area has been linked to poorer glycemic control and may reduce absorption by as much as $25 \%$. For this 
reason, regular assessment on injection sites and counseling regarding adequate site rotation should be emphasized at each clinic visit.

On storage of insulin, 7\% (3/46) were storing insulin in a cupboard and $41 \%$ (19/46) used refrigerators and frequent power interruptions was a challenge. This can have an effect on the biological activity of the insulin, especially for those storing it in cupboards affecting its potency as in normal cases, insulin has to be stored in temperatures between $2^{\circ} \mathrm{C}$ to $8^{\circ} \mathrm{C}$. The clay pot becomes the best insulin storage for most patients. Thus, health care providers need to be taught on how to prepare the clay pot and understand how it works, for them to teach the patients properly to ensure insulin potency is maintained.

In patients with type 1 , diabetes foot complications are the strongest predictor for mortality (Cusick, et al. 2005). Only 57\% (26/46) of the participants knew the importance of checking the feet daily for sores and cuts. In 2008 Rasli and Zacharin study assessing foot problems in children and adolescents with diabetes mellitus found that $68.8 \%$ of the participants had modifiable skin and nail disorders and 31.2\% muscoskeletal disorders. After giving their parents oral and written advice, there was a significant reduction of the disorders at follow up visits. This clearly shows how important the health education talks given to the patients and their families on selfcare are. For the adolescents to manage the diabetes and have good glycemic control, they need support. Psychological support has been identified to directly affect performance of diabetes self-care behaviors and indirectly affects their glycemic control (Osborn \& Egede, 2010). About $48 \%(10 / 21)$ of the participants received treatment adherence support from friends and $52 \%(11 / 21)$ psychological support from friends. This shows that friends play a crucial role in diabetes management during the adolescent period that can affect care positively or negatively. Bearman and La Greca (2002) reported that peer influence has a positive impact on behaviors such as increased blood sugar monitoring and dietary adherence. But literature review by Borus and Laffel (2010) found some studies showed no impact of peer influence on adherence. Considering the negative and positive impact peers have interventions need to in-cooperate peers into the adolescent patient care system.

Eleven percent $(13 / 121)$ of the participants received psychological support from family members. The inadequate psychological support from family could be from lack of knowledge by family members to provide the necessary support. Marshall, Carter and Rose (2006) highlighted that sometimes it becomes difficult for parents to offer necessary support to these adolescents with diabetes because they do not understand the type of support they require or how to behave in a supportive way. To deal with this, the best way would start with understanding the developmental stage at which these 
patients are. Adolescent stage is a period when they are discovering themselves and trying to be independent hence may come in conflict with managing the condition. During this stage, they usually prefer to live a normal life like their friends affecting their compliance to treatment (Dashiff, McCaleb and Cull, 2006). In the study by Palmer, et al. (2008) they insisted that for best metabolic control and prevention of developing complications, parental responsibility should be maintained despite factors like puberty as the child grows and becomes independent. Wolpert and Anderson (2001) however identified this stage as a window of opportunity for the clinician to shape the behavior that will help to determine the future health of young adults with diabetes. Therefore, this developmental stage does not only offer challenges but also opportunities to emphasize self-care practices.

\section{Study Limitations}

This study used a cross-sectional design. As such, it was difficult to establish the cause and effect. (causal factors). Furthermore, the study was conducted at QECH and $\mathrm{KCH}$ and involved the use of a small sample which limits generalization of study findings. However, the findings are significant and provide the whole valuable insight into issues affecting adolescents with diabetes in Malawi.

\section{Conclusion}

The findings of this study are consistent with research conducted in various countries in the Middle East, Asia and east Africa identifying limited knowledge among adolescents on diabetes and self-care practices. The current study identified inadequate knowledge on diabetes complications, management of hyperglycaemia, inappropriate self-monitoring of blood glucose, challenges in differentiating signs and symptoms of hyperglycaemia from hypoglycaemia and provision of too little psychological support neglecting the emotional needs of these adolescents.

Thus, education should be a continuous process to achieve targeted behavior change that leads to improved health status. There is need to develop education materials on diabetes and self-care practices targeting adolescent patients.

\section{References:}

1. Adeyemi, A. O., Rascati, K. L., Lawson, K. A., \& Strassels, S. A. (2012). Adherence to oral antidiabetic medications in the pediatric population with type 2 diabetes: a retrospective database analysis. Clinical Therapeutics. 34(3), 712-719.

2. Abioye-Kuteyi, E. A., Ojofeitimi, E. O., Ijadunola, K. T. \& Fasanu, A., O. (2005). Assessment of dietary knowledge, practices and 
control in type 2 diabetes in a Nigerian teaching hospital. Nigerian Journal of Medicine. 14(1),58-64.

3. Ahola, A. (2012, April 13). Psychological determinants and self care in patients with type 1 diabetes (Doctoral Thesis). University of Helsinki. Retrieved from https://helda.helsinki.fi/handle/10138/29792

4. Allen, D. A., Cohen, D., Robling, M. R., Hood, K., Atwell, C. L. A. \& Lane, C. et al. (2010). The transition from paediatric to adult diabetes services: what works, for whom and in what circumstances? Retrieved from http://www.netscc.ac.uk/hsdr/files/project/SDO_FR_08-1504 107_V01.pdf

5. Amer, S. S. S. (2005). Assessment of self-care practices among diabetic children in Jeddah city (Masters Thesis). King Saud University. Retrieved from http://repository.ksu.edu.sa/jspui/handle/123456789/8843

6. Alemzadeh, R., Loppnow, C., Parton, E. \& Kirby, M. (2003). Glucose sensor evaluation of glycemic instability in pediatric type 1 diabetes mellitus. Diabetes Technology Therapy. 5(2), 167-73

7. Bantle, J. P., Wylie-Rosett, J., Albright, A. L., Apovian, C. M., Clark, N. G. \& Franz, M. J. et al.

8. (2008). Nutrition recommendations and interventions for diabetes: a position statement of the American Diabetes Association. Diabetes Care. S61-78. doi: 10.2337/dc08-S061.

9. Bearman, K.J. \& La Greca, A.M. (2002). Assessing friend support of adolescents' diabetes care: the diabetes social support questionnairefriends version. Journal of Pediatric Psychology. 27(5), 417-428.

10. Borus, J.S. \& Laffel, L. (2010). Adherence challenges in the management of type 1 diabetes

11. in adolescents: prevention and intervention. Current Opinion on Pediatrics. 22(4), 405-411.

12. Buckloh, L.M., Lochrie, A.S., Antal, H., Milkes, A., Canas, J.A. \& Hutchinson, S. et al.

13. (2008). Diabetes complications in youth: qualitative analysis of parents' perspectives of family learning and knowledge. Diabetes Care. 31(8),1516-1520. Doi:10.2337/dc07-2349.

14. Chingatichifwe, B., Dodge, E., Chideme-Munodawafa, A., Mwale, C., \& Bvumbwe, $\mathrm{T}$.

15. (2014). Exploration of adoption of health lifestyle for secondary prevention of non - communicable diseases (Stroke, Diabetes and Hypertension) among clients at Mzuzu Central Hospital, Malawi. European Scientific Journal. 10(12), ISSN: 1857 - 7881 
16. Carroll, A., E., Downs, S., M. \& Marrero, D., G. (2007). What adolescents with type I diabetes and their parents want from testing technology. Computers, Informatics, Nursing. 25(1), 23-29

17. Clarke, S., F \& Foster, J., R. (2012). A history of blood glucose meters and their role in self-monitoring of diabetes mellitus. British Journal of Biomedical Science. 69(2), 83-93.

18. Cusick, M., Meleth, A.,D., Agron, E., Fisher, M.R., Reed, G.F. \& Knatterud, G.L. et al.

19. (2005). Associations of mortality and diabetes complications in patients with type 1 and type 2 diabetes. Diabetes Care. 28(3), 61725.

20. Delamater, A. M., 2006. Improving patient adherence. Clinical Diabetes; 24(2),71-77 Doi: 10.2337/diaclin.24.2.71.

21. Fitzgerald, J.T., Funnell, M.M., Anderson, R.M., Nwankwo, R., Stansfield, R.B., \& Piatt, G.A.

22. (2016). Validation of the Revised Brief Diabetes Knowledge Test (DKT2). The Diabetes Educator. 2016;42(2):178-187. doi:10.1177/0145721715624968.

23. Gulabani, M., John, M. \& Isaac, R. (2008). Knowledge of diabetes, its treatment and complications amongst diabetic patients in a tertiary care hospital. Indian Journal of Community Medicine. 33(3), 204206. Doi: 10.4103/0970-0218.42068.

24. Hoffman, M., Mofolo, I., Salima, C., Hoffman, I., Zadrozny, S. \& Martinson, F. et al. (2012). Utilization of family members to provide hospital care in Malawi: The role of hospital guardian. Malawi Medical Journal. 24(4), 74-78.

25. Hoffman, R., P. (2004). Practical management of type 1 diabetes mellitus in adolescent patients: challenges and goals. Treatments in Endocrinology. 3(1), 27-39.

26. Halvorson, M., Yasuda, P., Carpenter, S. \& Kaiserman, K. (2005). Unique challenges for pediatric patients with diabetes. Diabetes Spectrum 18(3), 167-173.

27. Kiawi, E., Edwards, R., Shu, J., Unwin N., Kamedjeu, R. \& Mbanya, J. (2006). Health beliefs, perceptions, knowledge and practices relative to diabetes and its major risk factors among urban residents in Cameroon: a qualitative survey. Ethnicityand disease. 16(2), 503509.

28. Marshal, M., Carter, B. \& Rose, K. (2006). Adolescents living with diabetes: Self-care and parental relationships. Journal of Diabetes Nursing. 10(1), 342-346

29. Motala, A. \& Ramaiya, K. (Eds.). (2010). Diabetes leadership forum Africa 2010: Diabetes the hidden pandemic and its impact on Sub- 
Saharan Africa. Retrieved from: www.idf.org/diabetes-leadershipforum-africa-2010.

30. Mufunda, E., Wikby, K., Björn, A. \& Hjelm, K. (2012). Level and determinants of diabetes knowledge in patients with diabetes in Zimbabwe: a cross-sectional study.The Pan African Medical Journal. 13,78. Retrieved from http://www.panafrican-medjournal.com/content/article/13/78/full/

31. Ntambalika, T. (2012). Building capacity for care and prevention in Malawi. Diabetes Voice, 57(2), 12-13.

32. Nansel, T.R., Haynie, D.L., Lipsky, L.M., Laffel, L.M. \& Mehta, S.N. (2012). Multiple indicators of poor diet quality in children and adolescents with type 1 diabetes are associated with higher body mass index percentile but not glycemic control. Journal of Academic Nutrition and Diet. 1728-35. Doi: 10.1016/j.jand.2012.08.029.

33. Palmer, D. L., Butler, A., Berg, C.J., Fortenberry, K., Murray, M. \& Lindsay, R. et al. (2008). Mothers, fathers and children's perceptions of parental diabetesresponsibility in adolescence: examining the roles of age, pubertal status, andefficacy. Journal of Paediatric Psychology 195-204. Doi:10.1093/jpepsy/jsn073.

34. Sigurdardottor, A. (2005). Self- care in diabetes; model of factors affecting selfcare.Journal of Clinical Nursing. 14(3), 301-314. World Health Organization. (2013). Diabetes. [Fact sheet]. Retrieved from http://www.who.int/mediacentre/factsheets/fs312/en/

35. Wysocki, T., Lochrie, A., Antal, H. \& Buckloh, L. M. (2011). Youth and parent knowledge

36. and communication about major complications of type 1 diabetes. Diabetes Care. 34(8), 1701-1705.

37. Yekta, Z., Pourali, R., Aghassi, M., R., Ashragh, N., Ravanyar, L. \& Pour, J. (2011).

38. Assessment of self-care practice and its Associated factors among diabetic patients in urban area of Urmia, northwest of Iran. Journal of Research in Health Sciences. 11(1),33-38. Retrieved from: www.umsha.ac.ir/jrhs 